\title{
Ghrelin reduces rat myocardial calcification induced by nicotine and vitamin $\mathrm{D} 3$ in vivo
}

\author{
FEI WANG ${ }^{1,2}$, TAO JIANG $^{1}$, CHAOSHU TANG $^{3}$, ZIJIE SU $^{1}$, NONG ZHANG $^{1}$ and GUIZHONG LI $^{2}$ \\ ${ }^{1}$ Department of Pathology, Shanghai Medical College, Fudan University, Shanghai 200032; ${ }^{2}$ Department of \\ Pathophysiology, Ningxia Medical University, Yinchuan 750004; ${ }^{3}$ Department of Physiology and \\ Pathophysiology, Peking University Health Science Center, Beijing 100069, P.R. China
}

Received April 1,2011; Accepted May 6, 2011

DOI: $10.3892 /$ ijmm.2011.710

\begin{abstract}
Ghrelin, a newly discovered bioactive peptide, initially was identified as a strong stimulant for the release of growth hormone $(\mathrm{GH})$ and that has improved cardiac function in patients suffering from end-stage chronic heart failure. Increasing evidence has demonstrated that ghrelin may have myocardial protective effects. However, the role of ghrelin in the pathogenesis of cardiovascular diseases remains unclear. In this study, an in vivo model of rat myocardial calcification induced by vitamin D3 and nicotine was used to study the possible mechanism in the regulatory action of ghrelin on the calcified myocardium. Calcification increased total $\mathrm{Ca}^{2+}$ content and ${ }^{45} \mathrm{Ca}^{2+}$ deposition in the myocardium and alkaline phosphatase (ALP) activation in the plasma. Compared with the control group, ghrelin mRNA expression was up-regulated and the myocardium calcium content was significantly increased in vitamin D3 and nicotine-treated rats. Rats were subcutaneously injected with 1 or $10 \mathrm{nmol} / \mathrm{kg}$ ghrelin. Rats treated with both low- and high-dose ghrelin decreased total $\mathrm{Ca}^{2+}$ content and ${ }^{45} \mathrm{Ca}^{2+}$ deposition in cardiac muscle and inhibited ALP activation in the myocardium and plasma, in a concentration-dependent manner. In addition, osteopontin
\end{abstract}

Correspondence to: Dr Guizhong Li, Department of Pathophysiology, Ningxia Medical University, 1160 Shengli Street, Yinchuan 750004, P.R. China

E-mail: ligzh@nxmu.edu.cn

Dr Nong Zhang, Department of Pathology, Shanghai Medical College, Fudan University, 138 Yixueyuan Road, Shanghai 200032, P.R. China E-mail: nzhang@fudan.edu.cn

Abbreviations: GH, growth hormone; ALP, alkaline phosphatase; OPN, osteopontin; P-OPN, phosphorylated OPN; ET, endothelin; VSMC, vascular smooth muscle cell; BMP, bone morphogenetic protein; ADM, adrenomedullin; CNP, C-type natriuretic peptide; PTHrP, parathyroid hormone-related peptide; GHSR, growth hormone secretagogue receptor; VDN, nicotine plus vitamin D3; MGP, matrix $\gamma$-carboxylated glutamate protein.

Key words: myocardium, calcification, ghrelin
(OPN) mRNA expression significantly decreased and that of endothelin (ET-1) significantly increased with myocardial calcification. Ghrelin treatment increased OPN expression at the mRNA level and reduced ET-1 mRNA expression in a dose-dependent manner. These results indicate that exogenous administration with ghrelin attenuates myocardial calcification induced by nicotine and vitamin D3, and that the possible mechanism is via the ghrelin-induced increase in the OPN mRNA levels and decrease in the ET- 1 mRNA expression in the myocardium.

\section{Introduction}

Cardiovascular calcification is a common finding in many cardiovascular diseases, such as hypertension, atherosclerosis, diabetes mellitus, chronic renal failure, aging, aortic stenosis, and prosthetic valve replacements, which is believed to be an important risk factor of cardiovascular diseases (1). Cardiovascular calcification decreases cardio- and vasodilatation, increases stiffness and promotes formation of thrombus and rupture of atherosclerotic plaques. However, the mechanism by which calcification induces cardiovascular dysfunction and remodeling remains unclear. Calcification was once considered a passive deposition of calcium and phosphorus in the extracellular matrix and in cells. Recent studies point out that cardiovascular calcification is an active, regulated process, similar to osteogenesis and osteoporosis (2). During the development of vascular calcification, vascular cells including vascular smooth muscle cells (VSMCs), pericytes, fibroblasts and macrophages, transform into an osteoblast-like phenotype, characterized by an increase in alkaline phosphatase (ALP) activity, matrix vesicle formation and overexpression of bone morphogenetic proteins (BMPs), including BMP-2 and bone matrix proteins, such as osteopontin (OPN), osteonectin, and osteocalcin (3-5).

We previously reported that adrenomedullin (ADM), C-type natriuretic peptide (CNP), and parathyroid hormone-related peptide (PTHrP) attenuated VSMCs calcification; however, ET and angiotensin II accelerated VSMCs calcification (6). Besides, calcified VSMCs is able to secrete ADM, resulting in elevated ADM mRNA levels in calcified cells (7). Exogenous administration of ADM inhibits rat vascular calcification by improving the vascular ADM/ADM receptor/cAMP pathway 
in vivo (8). These results show that cardiovascular bioactive peptides have important regulatory roles in cardiovascular calcification. Ghrelin, a 28 amino acid peptide, is a newly discovered hormone, produced principally in the stomach, and identified as the endogenous ligand for the growth hormone secretagogue receptor (GHSR) (9). Recently, ghrelin and its receptors were detected in cardiovascular tissues (10). It is thus possible that ghrelin may be acting directly on the heart and vasculature rather than it effects being mediated by growth hormone $(\mathrm{GH})(11)$. As an important autocrine/paracrine factor, ghrelin has various cardiovascular effects, including inotropic action, vasodilatation, anti-apoptosis, and antiinflammation (12-16), that indicate that ghrelin may maintain cardiovascular homeostasis.

Stimulation of GHSR has been showed to prevent cardiac damage after ischemia-reperfusion in hypophysectomized rats (17-22). Moreover, administration of ghrelin improved left ventricular dysfunction and attenuated the development of cardiac cachexia in a heart failure and shock model $(22,23)$. In our reports, we found that ghrelin inhibited ${ }^{45} \mathrm{Ca}^{2+}$ accumulation in cultured VSMCs in a concentration range from $10^{-10}$ to $10^{-7} \mathrm{M}$. Therefore, we hypothesized that ghrelin, as a paracrine/ autocrine factor of cardiac tissue, may have an effect on the myocardial calcification process. In this study we established a rat model of myocardial calcification with vitamin D3 and nicotine administration to assess the effects of ghrelin on rat myocardial calcification and study its mechanism of action.

\section{Materials and methods}

Animals and drugs. The Council on Animal Care at the Peking University approved this study protocol. Male Sprague Dawley (SD) rats weighing 150-180 g were supplied by the Animal Center, Health Science Center, Peking University. Vitamin D3, nicotine and ALP assay kits were purchased from SigmaAldrich (St. Louis, MO). ${ }^{45} \mathrm{CaCl}_{2}$ was obtained from NEN Life Science Products, Inc. (Boston, MA). Other chemicals and reagents were of analytical grade. The specific primers for OPN, ET-1, ghrelin and $\beta$-actin were synthesized by SBS Co. (Beijing, China). Ghrelin and ET-1 RIA kits were kindly provided by Phoenix Co. (USA).

Rat cardiovascular calcification model. An in vivo cardiovascular calcification model was produced according to the previously described method with minor modifications (24). Two-month-old male SD rats were randomly divided into control, nicotine plus vitamin D3 (VDN), VDN plus ghrelin $1 \mathrm{nmol} / \mathrm{kg} /$ day group (VDN+G1 group) and VDN plus ghrelin $10 \mathrm{nmol} / \mathrm{kg} /$ day group (VDN+G2 group), $\mathrm{n}=9$ in each group. On Day 1, rats in the VDN groups were injected with vitamin D3 (300,000 IU/kg, i.m.) and given nicotine dissolved in peanut oil ( $25 \mathrm{mg} / \mathrm{kg}$, p.o.). Nicotine administration was repeated $9 \mathrm{~h}$ later. Rats in the control group received an injection of normal saline (i.m.) and gavaged twice with peanut oil. The rats in VDN plus ghrelin groups were subcutaneously injected with ghrelin (1 and $10 \mathrm{nmol} / \mathrm{kg} /$ day, respectively in the VDN+G1 and the VDN+G2 groups), in addition to receiving VDN. All animals were maintained on normal rat chow in a 12:12 h light-dark cycle and were given water ad libitum. The rats were caged individually after the initial treatment. After the end of 4 weeks all rats were anesthetized with urethan $(1 \mathrm{~g} / \mathrm{kg}$, i.p.) and sacrificed. Blood was collected into a tube pre-treated with EDTA-Na 2 (1 mg/ml), aprotinin (500 kIU), and plasma was separated by centrifugation $(1,600 \mathrm{x} g, 15 \mathrm{~min})$. The hearts were harvested, weighed and stored at $-70^{\circ} \mathrm{C}$.

Measurement of calcium content in the myocardium. The $20 \mathrm{mg}$ of ventricular myocardium was dissolved in $\mathrm{HNO}_{3}$, completely dried, and then diluted with a blank solution (27 nmol/1 KCl, $27 \mu \mathrm{mol} / 1 \mathrm{LaCl}_{3}$ ). The calcium content was determined with an atomic absorption spectrophotometer at $422.7 \mathrm{~nm}(25)$.

Von Kossa staining for calcification. The protocol for von Kossa calcium staining of rat myocardium has been previously described (26). Briefly, a segment of the myocardium was excised and fixed in $10 \%$ formalin. Tissue samples were dehydrated and embedded in paraffin, then cut into $6-\mu \mathrm{m}$ sections. The slides were deparaffinized and dehydrated before incubation in $5 \%$ silver nitrate solution for $30 \mathrm{~min}$ in the sun, and then washed with a solution of $5 \%$ sodium thiosulfate for $2 \mathrm{~min}$. Finally, slides were counterstained with safranine (red staining) and examined under a light microscope by two individuals blinded to the treatment conditions.

Measurement of ALP activity in the myocardium. A homogenate of ventricular myocardium was prepared by Polytron in homogenizing buffer $(20 \mathrm{mmol} / 1 \mathrm{HEPES}, \mathrm{pH} 7.4$, containing $0.2 \% \mathrm{NP}-40$, and $20 \mathrm{mmol} / 1 \mathrm{MgCl}_{2}$ ). The supernatant was collected following centrifugation at $8,000 \times \mathrm{g}$ for $10 \mathrm{~min}$. ALP activity was determined by mixing $200 \mathrm{mg}$ protein sample (in $200 \mathrm{ml}$ ) with $1 \mathrm{ml}$ reaction mixture (alkaline buffer, stock substrate solution 1:1) and incubated at $37^{\circ} \mathrm{C}$ for $30 \mathrm{~min}$. The stock substrate solution was prepared by dissolving the contents of a $100 \mathrm{mg}$ capsule of Sigma 104 phosphatase substrate in $25 \mathrm{ml}$ of $\mathrm{dd}_{2} \mathrm{O}$. The reaction was stopped by addition of $20 \mathrm{ml}$ of $1 \mathrm{~mol} / 1 \mathrm{NaOH}$, and the absorbance at $405 \mathrm{~nm}$ was determined. The ALP activity was calculated using p-nitrophenol as a standard. One unit was defined as the activity produced by $1 \mathrm{nmol}$ of p-nitrophenol within $30 \mathrm{~min}$ (25).

${ }^{45} \mathrm{Ca}^{2+}$ uptake measurement. To determine ${ }^{45} \mathrm{Ca}^{2+}$ accumulation in heart tissues, $20 \mathrm{mg}$ of ventricular myocardium was sliced by a slicer and placed in $1 \mathrm{ml}$ Krebs-Henseleit (K-H) solution (in mmol/l: $\mathrm{NaCl} 118, \mathrm{KCl} 4.7, \mathrm{CaCl}_{2} 1.3, \mathrm{KH}_{2} \mathrm{PO}_{4} 1.2, \mathrm{MgSO}_{4}$ 1.2, $\mathrm{NaHCO}_{3} 25$ and glucose 11, $\mathrm{pH} 7.4$ ), then, $37 \mathrm{kBq} / \mathrm{ml}$ of ${ }^{45} \mathrm{CaCl}_{2}$ were added. After $8 \mathrm{~h}$ incubation, the reaction was stopped by addition of ice-cold $0.2 \mathrm{~mol} / 1$ phosphate-buffer solution ( $\mathrm{pH} 7.4$ ). The tissue was dissolved with $88 \%$ formic acid at $80^{\circ} \mathrm{C}$ for $4 \mathrm{~h} .{ }^{45} \mathrm{Ca}^{2+}$-radioactivity was measured by a $\beta$-scintillation counter (Beckman LS 6500) (25).

Radioimmunoassay of endothelin and ghrelin levels in plasma. The acidulated plasma was applied to a Sep-Pak C18 cartridge (Millipore-Waters, Milford, MA, USA). After washing the cartridge with $10 \mathrm{CH}_{3} \mathrm{CN}$ in $0.1 \%$ trifluoroacetic acid, the absorbed materials were eluted with $50 \% \mathrm{CH}_{3} \mathrm{CN}$ in $0.1 \%$ trifluoroacetic acid, lyophilized and stored at $-70^{\circ} \mathrm{C}$ until assayed. Endothelin and ghrelin levels in the plasma were 
A

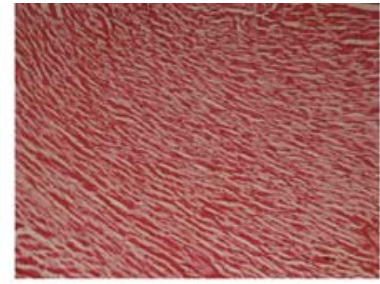

B

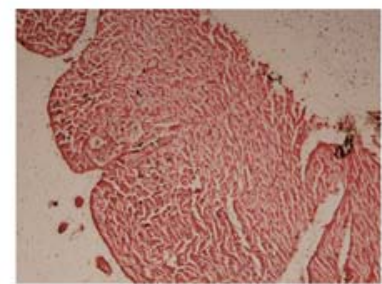

$\mathrm{C}$

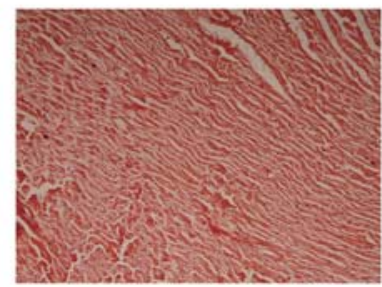

D

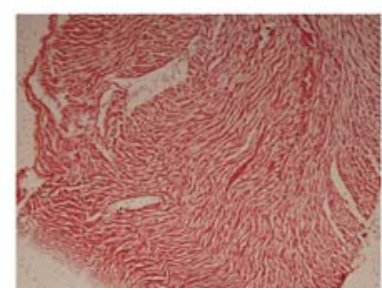

$\mathrm{E}$

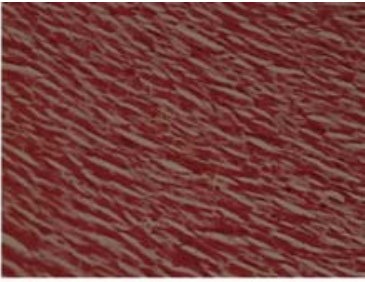

F

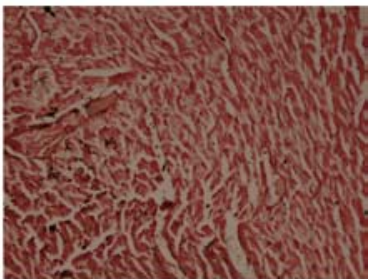

G

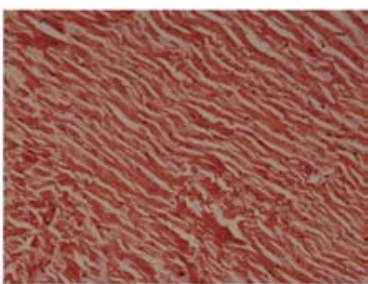

H

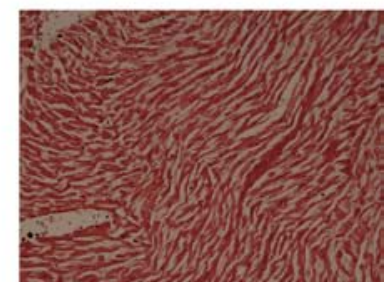

Figure 1. Von Kossa staining for myocardial calcification, showing a strong positive staining of black/brown areas among the myocardial matrix (original magnification $\mathrm{x} 200$ in A-D, and $\mathrm{x} 400$ in E-H). A and E, controls; B and $\mathrm{F}$, calcified myocardium; $\mathrm{C}$ and $\mathrm{G}$, calcified myocardium treated with $1 \mathrm{nmol} / \mathrm{kg} /$ day ghrelin for 4 weeks; D and $\mathrm{H}$, calcified myocardium treated with $10 \mathrm{nmol} / \mathrm{kg} /$ day ghrelin for 4 weeks.

measured using a specific radioimmunoassay (RIA) kit for ET and ghrelin, respectively (27). Rabbit polyclonal anti-ET and anti-ghrelin were used for RIA in these kits. The $\mathrm{IC}_{50}$ for rat ET was $14.6 \mathrm{pg} /$ tube. The cross-reactivity with rat ET was $100 \%$, and that with ET-2, ET-3 and angiotensin II was 3.5, 28 and $0 \%$, respectively. The $\mathrm{IC}_{50}$ for rat ghrelin was $6.9 \mathrm{pmol} / \mathrm{tube}$, and binding was $35 \%$ in this assay. There was $100 \%$ crossreactivity with rat and human ghrelin. All assays included 12 plasma control samples from common stock solutions, which were frozen in aliquots at the beginning of the study, in order to normalize each test for inter-assay variability. Based on these controls, the intraassay coefficient of variation was $8.7 \%$ and the interassay coefficient of variation was $14.6 \%(n=10)$. No cross-reactivity was seen with leptin, orexin A and B, neuropeptide $\mathrm{Y}$, galanin or vasoactive intestinal polypeptide, assessed with doubling dilutions from 100 to $1 \mathrm{ng} / \mathrm{ml}$.

RT-PCR for OPN, endothelin and ghrelin mRNA. Total-RNA from myocardium was extracted with TRIzol (Gibco-BRL, Rockville, MD) reagent (28). RT-PCR was performed in a total volume of $25 \mu \mathrm{l}$. The PCR products were separated on a $1.5 \%$ agarose gel, and stained with ethidium bromide. The ratio of optical densities of OPN, ET and ghrelin mRNA to

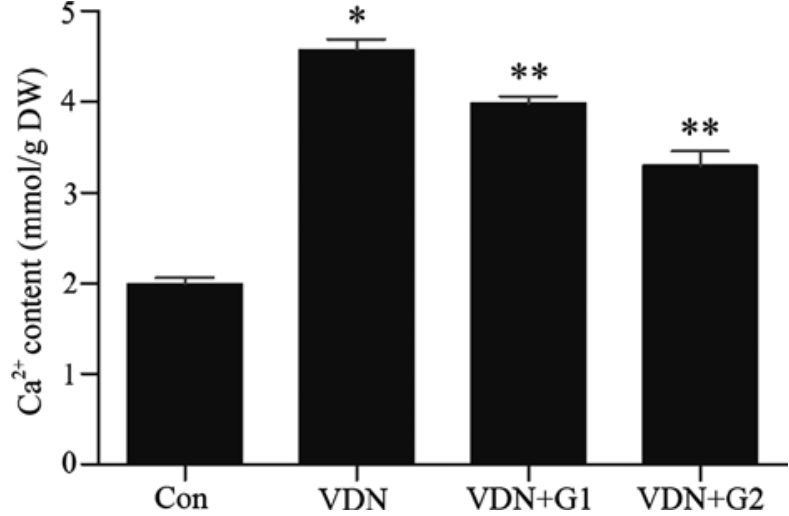

Figure 2. The myocardial calcium contents. Data are shown as means \pm SEM The myocardial calcium content was measured as described in Materials and methods. VDN significantly induced calcium accumulation in the myocardium. Ghrelin administration significantly reduces calcium contents in the myocardium. ${ }^{*} \mathrm{P}<0.01$ vs. the control group; ${ }^{* *} \mathrm{P}<0.01$ vs. the VDN group. $\mathrm{n}=9$ for each group. Con, control; VDN, nicotine plus vitamin D3; G1, G2, 1 and $10 \mathrm{nmol} / \mathrm{kg} /$ day ghrelin.

$\beta$-actin were measured using the Gel Documentation System (Bio-Rad, Hercules, CA). Oligonucleotides were synthesized by Sai Baisheng Biotechnology (Beijing, China). The sequences of the oligonucleotide primers were as follows: ghrelin-S, 5'-TTGAGCCCAGAGCACCAGAAA-3'; ghrelin-A, 5'-AGT TGCAGAGGAGGCAGAAGCT-3'; OPN-S, 5'-CTCGCGGT GAAAGTGGCTGA-3'; OPN-A, 3'-GACCTCAGAAGAT GAACTCT-5'; ET-S, 5'-GGTCTTGATGCTGTTGCTGA-3'; ET-A, 5'-GAGCTGAGAAGGAAGTGCAGA-3', as well as $\beta$-actin-S, 5'-ATCTGGCACCACACCTTC-3'; and $\beta$-actin-A, 5'-AGCCAGGTCCAGACGCA-3' for calibration of sample loading. Other chemicals and reagents were of analytical grade.

Statistical analysis. Data were expressed as mean \pm SEM. One-way ANOVA followed by the Student Newman-Keuls test were performed. A two-tailed $\mathrm{P}<0.05$ was considered statistically significant.

\section{Results}

Calcium deposits in the myocardium. Control myocardium showed no calcified deposits (Fig. 1A and E), but calcified myocardium showed strong positive staining among the myocardial matrix (Fig. 1B and 1F). After ghrelin treatment of 1 (Fig. $1 \mathrm{C}$ and $\mathrm{G}$ ) or $10 \mathrm{nmol} / \mathrm{kg} /$ day (Fig. 1D and $\mathrm{H}$ ) for 4 weeks, the positive staining in the myocardial matrix was decreased compared to that in the calcified myocardium. The data indicate that ghrelin reduces the deposition of calcium within the myocardial matrix.

Ghrelin reduces the myocardial calcium content induced by $V D N$. Nicotine and vitamin D3 (VDN) are potent agents used in calcification models to induce $\mathrm{Ca}^{2+}$ accumulation in the myocardium and vascular tissues (24). As shown in Fig. 2, the myocardium calcium content was significantly increased $(129 \%, \mathrm{P}<0.01)$ in the VDN group compared with the control group. Treatment of rats with ghrelin significantly decreased myocardium calcium contents. The myocardial calcium contents 

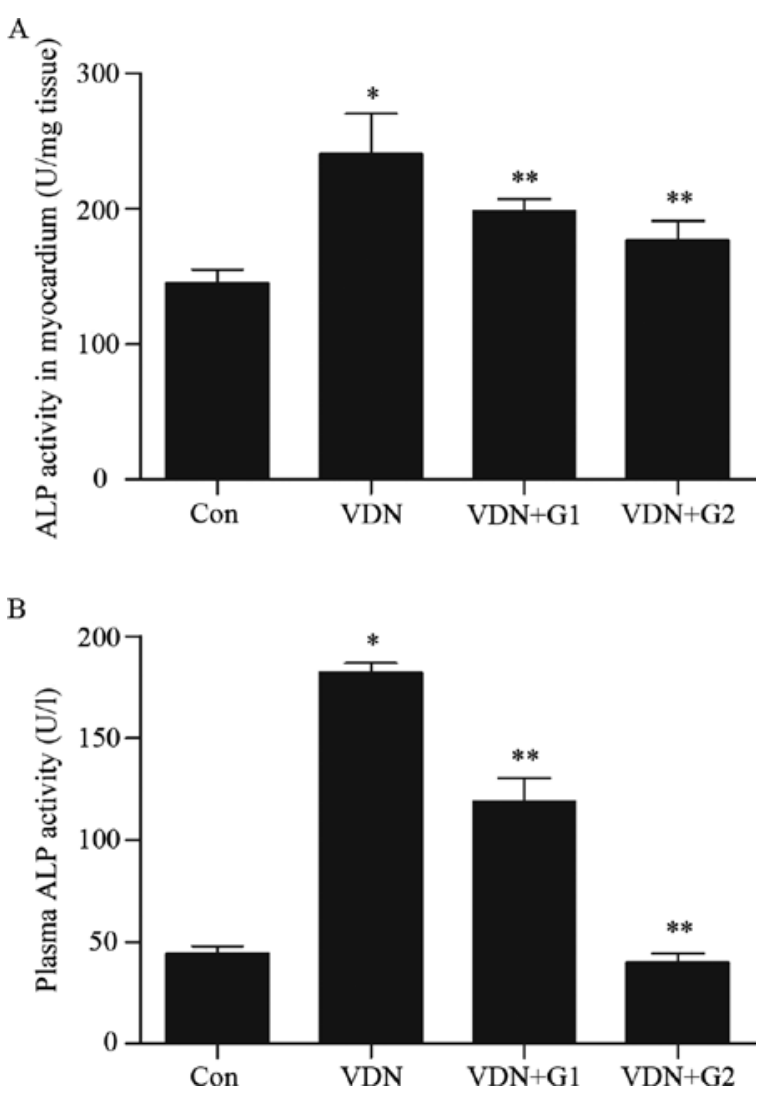

Figure 3. ALP activity in myocardium and plasma. ALP activity was measured as described in Materials and methods. VDN increased ALP activity in myocardium (A) and plasma (B), whereas administration with ghrelin [both 1 (G1) and 10 (G2) nmol/kg/dayl inhibited ALP activity induced by VDN. ${ }^{*} \mathrm{P}<0.01$ vs. control (Con) group; ${ }^{* * *} \mathrm{P}<0.01$ vs. VDN group. $\mathrm{n}=9$ in each group.

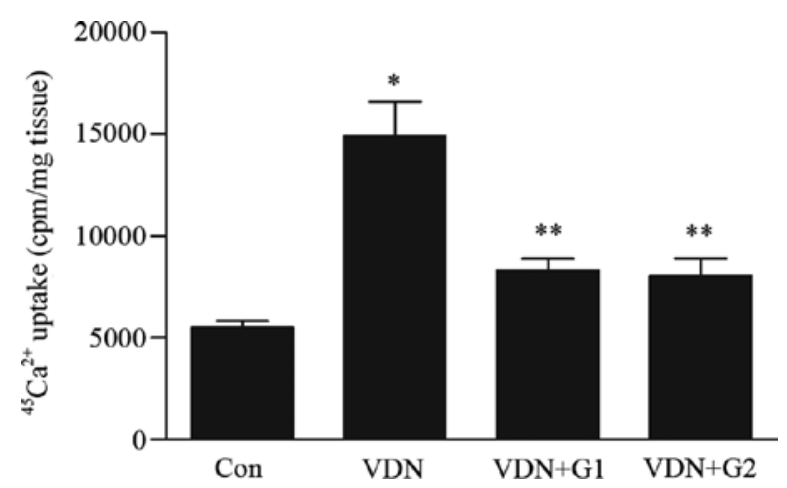

Figure $4 .{ }^{45} \mathrm{Ca}^{2+}$ uptake in the myocardium. Myocardial ${ }^{45} \mathrm{Ca}^{2+}$ uptake was measured as described in Materials and methods. Data shown are the means \pm SEM. VDN stimulated myocardial ${ }^{45} \mathrm{Ca}^{2+}$ uptake, but treatment with $1(\mathrm{G} 1)$ or $10(\mathrm{G} 2) \mathrm{nmol} / \mathrm{kg} /$ day ghrelin significantly inhibited myocardial ${ }^{45} \mathrm{Ca}^{2+}$ uptake stimulated by VDN. ${ }^{*} \mathrm{P}<0.01$ vs. control (Con) group; ${ }^{* *} \mathrm{P}<0.01$ vs. VDN group. $\mathrm{n}=9$ for each group.

were decreased by $13 \%(\mathrm{P}<0.01)$ and $28 \%(\mathrm{P}<0.01)$ in rats treated with 1 and $10 \mathrm{nmol} / \mathrm{kg} /$ day of ghrelin, respectively, in comparison to the VDN alone group. The calcium content in the $\mathrm{VDN}+\mathrm{G} 2$ group was lower than that in the $\mathrm{VDN}+\mathrm{G} 1$ group $(\mathrm{P}<0.01)$.

Ghrelin inhibits ALP activity activated by VDN in the plasma and myocardium. ALP is a specific enzyme that promotes calcium deposition in tissues. Administration to rats with

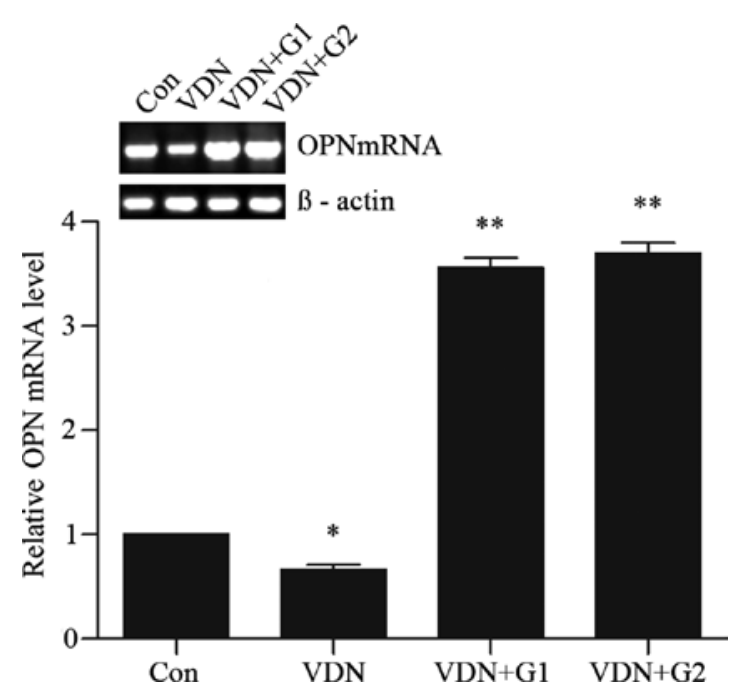

Figure 5. RT-PCR for OPN mRNA in myocardium. The OPN mRNA level in myocardium was down-regulated in VDN group $\left({ }^{*} \mathrm{P}<0.05\right)$. The OPN mRNA levels were up-regulated after treatment with ghrelin 1 and $10 \mathrm{nmol} /$ $\mathrm{kg} / \mathrm{day}$, and were increased by 89 and $96 \%$ respectively than that in VDN alone group (all $\left.{ }^{* *} \mathrm{P}<0.01\right)$.

VDN significantly increased ALP activity in the myocardium, to levels that were $65 \%$ higher than those in the control group $(\mathrm{P}<0.01)$. However, ghrelin administration to VDN-treated rats significantly inhibited ALP activation in the myocardium. The inhibition rates were 18 and $27 \%$, respectively, in the $\mathrm{VDN}+\mathrm{G} 1$ and $\mathrm{VDN}+\mathrm{G} 2$ groups, compared with the VDN alone group $(\mathrm{P}<0.01)$ (Fig. 3A). In physiological conditions, ALP mainly exists in the cytoplasm. It will leak out into the blood plasma when cells are injured. The plasma ALP activity was significantly increased in the VDN group in comparison to the control $(\mathrm{P}<0.01)$ (Fig. 3B). However, the plasma ALP activity was obviously reduced in the ghrelin-treated groups compared with the VDN alone group $(\mathrm{P}<0.01)$. Both in the myocardium and plasma, ALP activity was lower in the $\mathrm{VDN}+\mathrm{G} 1$ than in the $\mathrm{VDN}+\mathrm{G} 2$ group $(\mathrm{P}<0.01)$.

Ghrelin reduces calcium accumulation in the myocardium induced by VDN. As shown in our experiments, the myocardial ${ }^{45} \mathrm{Ca}^{2+}$ uptake was 2.7 -fold higher in rats treated with VDN alone than in controls $(\mathrm{P}<0.01$, Fig. 4). However, administration with ghrelin significantly attenuated myocardial ${ }^{45} \mathrm{Ca}^{2+}$ uptake by $44 \%$ in the $\mathrm{VDN}+\mathrm{G} 1$ and by $46 \%$ in the $\mathrm{VDN}+\mathrm{G} 2$ groups, respectively, compared with the VDN alone group $(\mathrm{P}<0.01)$ (Fig. 4).

Ghrelin up-regulates myocardial OPN mRNA levels. OPN is a regulatory protein for tissue calcium deposition. OPN mRNA levels in the myocardium were down-regulated in the VDN group (Fig. 5). However, OPN mRNA levels were up-regulated after treatment with 1 and $10 \mathrm{nmol} / \mathrm{kg} / \mathrm{day}$ ghrelin, and were increased by 89 and $96 \%$, respectively, compared to the VDN alone group (all $\mathrm{P}<0.01)$.

Effects of ghrelin on ghrelin and ET-1 levels in the myocardium and plasma. As shown in Fig. 6, ET-1 mRNA levels in the myocardium were $17 \%$ higher in the VDN group than in the control group $(\mathrm{P}<0.05)$. Interestingly, rats treated with ghrelin 


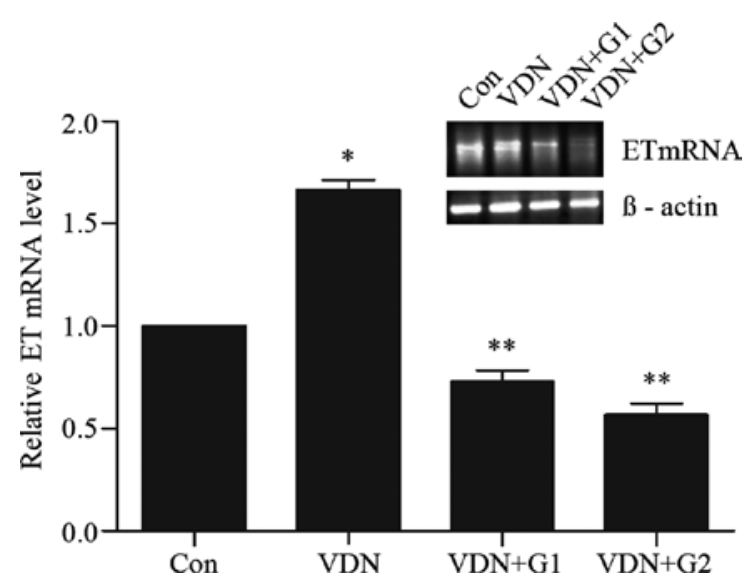

Figure 6. RT-PCR for ET-1 mRNA levels in the myocardium. ET-1 mRNA levels in the myocardium were $17 \%$ higher in the VDN group than in the control (Con) group ( $\left.{ }^{*} \mathrm{P}<0.05\right)$. The ET-1 mRNA levels were decreased by $61 \%$ in the $\mathrm{VDN}+\mathrm{G} 1$ group and by $78 \%$ in the $\mathrm{VDN}+\mathrm{G} 2$ group compared with the VDN alone group (all $\mathrm{P}<0.01$ ). G1, G2, 1 and $10 \mathrm{ng} / \mathrm{kg} /$ day ghrelin.

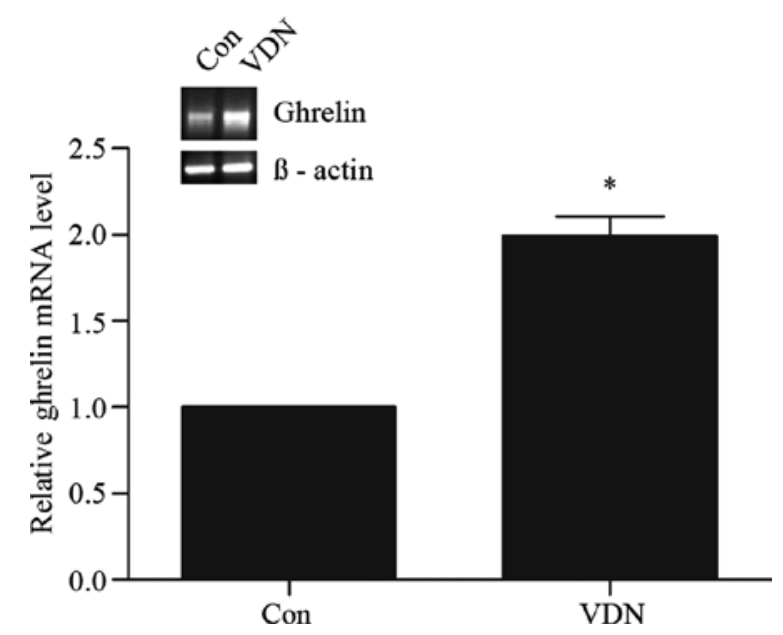

Figure 7. RT-PCR for ghrelin mRNA levels in the myocardium. Ghrelin mRNA levels were $50 \%$ higher in the myocardium of rats treated with VDN than in that of controls $(\mathrm{P}<0.01)$.

significantly down-regulated ET-1 mRNA expression in the myocardium. ET-1 mRNA levels were decreased by $61 \%$ in the $\mathrm{VDN}+\mathrm{G} 1$ group and by $78 \%$ in the $\mathrm{VDN}+\mathrm{G} 2$ group compared with the VDN alone group (all $\mathrm{P}<0.01$ ). However, ET-1 levels in the plasma were not statistically different among the experimental groups (all $\mathrm{P}>0.05$ ) (Fig. 8A). To determine the ghrelin mRNA levels expressed in the calcified myocardium, we assayed ghrelin mRNA by the RT-PCR method. Ghrelin mRNA was $50 \%$ higher in the myocardium of rats treated with VDN than that in controls $(\mathrm{P}<0.01)$ (Fig. 7). However, plasma ghrelin levels were slightly decreased (15\%) in the VDN group, compared with the control group $(\mathrm{P}<0.05)$ (Fig. 8B).

\section{Discussion}

It is universally considered that vascular calcification is a severe risk factor. Recently, growing evidence shows that tissue calcification during cardiovascular diseases occurs not only in the vascular vessels and cardiac valves but also in the myocardium, especially during end-stage renal disease (2).
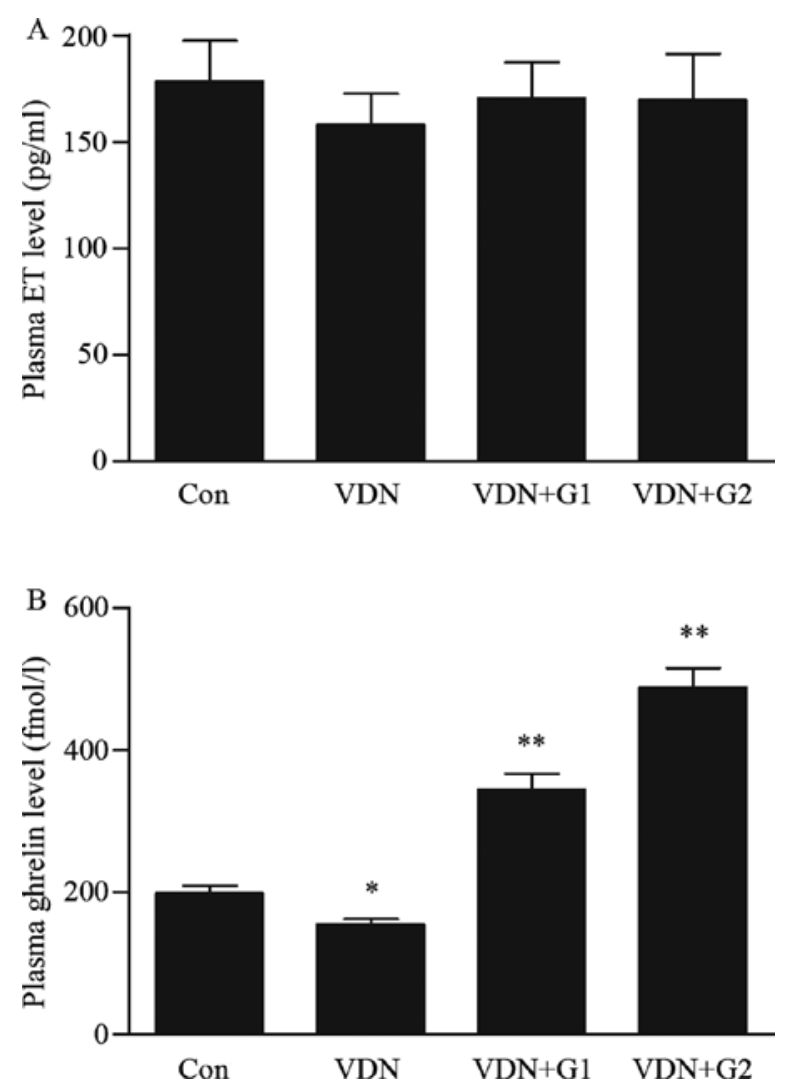

Figure 8. Plasma ET-1 and ghrelin levels. Plasma ET-1 and ghrelin levels were determined with RIA methods. The ET-1 levels were not statistically different among the groups (A). VDN treatment slightly decreased plasma ghrelin levels. The plasma ghrelin levels were significantly higher in the ghrelin treated group than in the VDN group (B). ${ }^{*} \mathrm{P}<0.01 \mathrm{vs}$. the control (Con) group; ${ }^{* *} \mathrm{P}<0.01$ vs. the VDN group. $\mathrm{n}=9$ for each group.

Calcium crystals deposit extensively on the heart muscle, and calcium overload occurs in the myocardial cells. Calcium accumulation in the myocardium has a deleterious effect on cardiac performance $(2,29)$. Rostand and colleagues found myocardial calcification with a reduction in myocardial performance and even heart failure in patients undergoing dialysis (3). However, the mechanism of cardiac dysfunction during myocardial calcification is unknown. Cardiovascular calcification is not a 'passive' crystallization process, but a biologically active one (2). It is considered an actively regulated process similar to osteogenesis and osteoporosis (30). Calcified cells with an osteoblast-like cell phenotype traits are the cellular basis of calcification pathogenesis (31). When matrix vesicles appear in the cells, they synthesize large amounts of bone matrix protein and ALP, causing calcium deposit in cells and extracellular matrix. Growing evidence indicates that cardiovascular bioactive peptides are involved in regulating cardiovascular calcification, such as angiotensin II (32), platelet-derived growth factor (33), CNP, PTHrP, ET-1 and adrenomedulin (6). Ghrelin, a recently discovered 28 amino acid peptide, has received considerable attention for its effects on food intake and adiposity, in addition to its GH-releasing properties (34). Putative receptors for ghrelin have been identified in blood vessels and cardiomyocytes, suggesting that the peptide could play a modulatory role in cardiovascular function (18). 
The administration of VDN induces calcium overload in arteries, media calcification, and, finally, widespread cardiovascular calcification (24). We used VDN to investigate myocardial calcification in rats. After 4 weeks of treatment, calcium contents, $\mathrm{Ca}^{2+}$ accumulation, and ALP activity in the myocardium increased significantly, in accordance with the results of previous research (24). Interestingly, all three of these parameters were significantly inhibited by ghrelin administration, suggesting that ghrelin exerts protective effects on myocardial calcification induced by VDN.

The underlying mechanisms of the ghrelin-induced inhibition of myocardial calcification remain unclear. Growing evidence suggests that cardiovascular calcification is a biologically regulated phenomenon and may be subject to prevention and reversal (2). The calcified cells synthesize and secrete major components of bone osteoid, such as ALP, BMP-2, OPN. OPN and matrix $\gamma$-carboxylated glutamate protein (MGP), which may regulate the amount of calcium deposited in the cardiovascular tissues (3). Our results indicate that VDN significantly inhibites OPN mRNA expression in the myocardium. Administration of ghrelin markedly induced OPN mRNA expression which was accompanied with a reduction of myocardial calcium content and $\mathrm{Ca}^{2+}$ accumulation, suggesting that the beneficial effects of ghrelin on myocardial calcification were related to the stimulation of OPN expression. OPN is a non-collagenous, glycosylated phosphoprotein associated with biomineralization in osseous tissues, as well as ectopic calcification. Jono and Giachelli (35) reported that OPN is co-localized with calcified deposits in atherosclerotic lesions, and that OPN potently inhibited calcium deposition in a human smooth muscle cell (HSMC) culture model of vascular calcification. They further report that the ability of OPN to inhibit calcification completely depends on posttranslational modifications, since bacteria-derived recombinant OPN did not inhibit HSMC mineralization. Phosphorylated OPN (P-OPN) dose-dependently inhibited calcification of HSMC cultured in vitro, while none of the non-phosphorylated OPN fragments affected calcification. P-OPN was treated with ALP to create dephosphorylated OPN. Dephosphorylated OPN dose not have an inhibitory effect on calcification. The expression of OPN mRNA and P-OPN secretion by HSMC were decreased in a time-dependent manner during calcification of cultured cells.

The peptide ET-1 is a potent and long-lasting vasoconstrictor and mitogen. It was reported that ghrelin $(0.1-300 \mathrm{nmol} / \mathrm{l})$ potently dilated human arteries constricted by $10 \mathrm{nmol} / \mathrm{l}$ ET-1 treatment, indicating that ghrelin is an effective and natural antagonist of the long-lasting constrictor ET-1 (36). Our results show that VDN increased ET-1 mRNA levels in the myocardium. This effect was significantly inhibited by ghrelin administration. However, ghrelin did not affect plasma ET-1 levels in this model. This phenomenon could result from the ET-1 as a paracrine/autocrine factor in cardiovascular tissues. ET-1 was reported to modulate bone metabolism both in vivo and in vitro (37-38). ET-1 time- and dose-dependently stimulated Na-dependent Pi transport in mouse calvaria-derived osteoblastlike MC3T3-E1 cells. Kinetic analysis indicated that the changes in Pi transport activity induced by ET-1 were due to the alteration of the number of Pi transporters. It could be one of the anti-calcification mechanisms of ghrelin that ghrelin inhibits ET-1 gene expression and antagonizes the biological effect of ET-1 (39).

The results in this study demonstrate that ghrelin mRNA levels were up-regulated and ghrelin level changed in the myocardial calcified model. This result may be a compensatory response of the local calcified myocardium. Exogenous ghrelin administration significantly attenuated myocardial calcification. Our data suggest that ghrelin may be an important para/autocrine factor regulating cardiovascular calcification. The beneficial effects of ghrelin on the cardiovascular system will be a new target for preventing cardiovascular diseases, such as cardiovascular calcification and heart failure.

\section{References}

1. Burke AP, Weber DK, Kolodgie FD, Farb A, Taylor AJ and Virmani R: Pathophysiology of calcium deposition in coronary arteries. Herz 26: 239-244, 2001.

2. Farzaneh-Far A, Proudfoot D, Shanahan C and Weissberg PL: Vascular and valvar calcification: recent advances. Heart 85: 13-17, 2001.

3. Rostand SG, Sanders C, Kirk KA, Rutsky EA and Fraser RG: Myocardial calcification and cardiac dysfunction in chronic renal failure. Am J Med 85: 651-657, 1988.

4. Alfaro MP, Vincent A, Saraswati S, et al: sFRP2 suppression of bone morphogenic protein (BMP) and Wnt signaling mediates mesenchymal stem cell (MSC) self-renewal promoting engraftment and myocardial repair. J Biol Chem 285: 35645-35653, 2010.

5. Kang YH, Jin JS, Yi DW and Son SM: Bone morphogenetic protein-7 inhibits vascular calcification induced by high vitamin D in mice. Tohoku J Exp Med 221: 299-307, 2010.

6. Huang Z, Li J, Jiang Z, Qi Y, Tang C and Du J: Effects of adrenomedullin, $\mathrm{C}$-type natriuretic peptide, and parathyroid hormone-related peptide on calcification in cultured rat vascular smooth muscle cells. J Cardiovasc Pharmacol 42: 89-97, 2003.

7. Qi YF, Wang SH, Zhang BH, Bu DF, Shu TC and Du JB: Changes in amount of ADM mRNA and RAMP2 mRNA in calcified vascular smooth muscle cells. Peptides 24: 287-294, 2003.

8. Zhang B, Tang C, Jiang Z, Qi Y, Pang Y and Du J: Effects of adrenomedullin on vascular calcification in rats. Z Kardiol 91: 568-574, 2002.

9. Kojima M HH, Date Y, Nakazato M, Matsuo H and Kangawa K: Ghrelin is a growth-hormone-releasing acylated peptide from stomach. Nature 402: 656-660, 1999.

10. Nagaya N, Kojima M, Uematsu M, et al: Hemodynamic and hormonal effects of human ghrelin in healthy volunteers. Am J Physiol Regul Integr Comp Physiol 280: R1483-R1487, 2001.

11. Isgaard J, Barlind A and Johansson I: Cardiovascular effects of ghrelin and growth hormone secretagogues. Cardiovasc Hematol Disord Drug Targets 8: 133-137, 2008.

12. Nagaya N, Miyatake K, Uematsu M, et al: Hemodynamic, renal, and hormonal effects of ghrelin infusion in patients with chronic heart failure. J Clin Endocrinol Metab 86: 5854-5859, 2001.

13. Baldanzi G, Filigheddu N, Cutrupi S, Catapano F, Bonissoni S, Fubini A, Malan D, Baj G, Granata R, Broglio F, Papotti M, Surico N, Bussolino F, Isgaard J, Deghenghi R, Sinigaglia F, Prat M, Muccioli G, Ghigo E and Graziani A: Ghrelin and des-acyl ghrelin inhibit cell death in cardiomyocytes and endothelial cells through ERK1/2 and PI3-kinase/AKT. J Cell Biol 159: 1029-1037, 2002.

14. Li WG, Gavrila D, Liu X, Wang L, Gunnlaugsson S, Stoll L, McCormick M, Sigmund C, Tang C and Weintraub N: Ghrelin inhibits proinflammatory responses and nuclear factor-kappa $\mathrm{B}$ activation in human endothelial cells. Circulation 109: 2221-2226, 2004.

15. Huang CX, Yuan M, Huang H, Wu G, Liu Y, Yu SB, Li HT and Wang T: Ghrelin inhibits post-infarct myocardial remodeling and improves cardiac function through anti-inflammation effect. Peptides 30: 2286-2291, 2009.

16. Xu Z, Lin S, Wu W, Tan H, Wang Z, Cheng C, Lu L and Zhang X: Ghrelin prevents doxorubicin-induced cardiotoxicity through TNF-alpha/NF-kappaB pathways and mitochondrial protective mechanisms. Toxicology 247: 133-138, 2008. 
17. Papotti M, Ghe C, Cassoni P, et al: Growth hormone secretagogue binding sites in peripheral human tissues. J Clin Endocrinol Metab 85: 3803-3807, 2000.

18. Gnanapavan S, Kola B, Bustin SA, et al: The tissue distribution of the mRNA of ghrelin and subtypes of its receptor, GHS-R, in humans. J Clin Endocrinol Metab 87: 2988, 2002.

19. Li L, Zhang LK, Pang YZ, et al: Cardioprotective effects of ghrelin and des-octanoyl ghrelin on myocardial injury induced by isoproterenol in rats. Acta Pharmacol Sin 27: 527-535, 2006.

20. Schwenke DO, Tokudome T, Kishimoto I, et al: Early ghrelin treatment after myocardial infarction prevents an increase in cardiac sympathetic tone and reduces mortality. Endocrinology 149: 5172-5176, 2008.

21. Chang L, Ren Y, Liu X, et al: Protective effects of ghrelin on ischemia/reperfusion injury in the isolated rat heart. J Cardiovasc Pharmacol 43: 165-170, 2004.

22. Nagaya N, Uematsu M, Kojima M, et al: Chronic administration of ghrelin improves left ventricular dysfunction and attenuates development of cardiac cachexia in rats with heart failure. Circulation 104: 1430-1435, 2001.

23. Chang L, Zhao J, Yang J, Zhang Z, Du J and Tang C: Therapeutic effects of ghrelin on endotoxic shock in rats. Eur J Pharmacol 473: 171-176, 2003.

24. Niederhoffer N, Bobryshev YV,Lartaud-Idjouadiene I, Giummelly P and Atkinson J: Aortic calcification produced by vitamin D3 plus nicotine. J Vasc Res 34: 386-398, 1997.

25. Hsu HH, Tawfik O and Sun F: Effects of lectins on calcification by vesicles isolated from aortas of cholesterol-fed rabbits. Biochim Biophys Acta 1464: 262-272, 2000.

26. Shioi A, Nishizawa Y, Jono S, Koyama H, Hosoi M and Morii H: Beta-glycerophosphate accelerates calcification in cultured bovine vascular smooth-muscle cells. Arterioscler Thromb Vasc Biol 15: 2003-2009, 1995

27. Savage $P$ and Jeng AY: Quantitation of plasma endothelins. Anal Biochem 213: 434-436, 1993.

28. Liu P, Chen H, Cheng Y, Zeng FD and Tang CS: Changes of osteopontin and matrix Gla protein mRNA expressions in the healing process of rat thoracic aorta damaged by balloon angioplasty. Sheng Li Xue Bao 51: 541-547, 1999 (In Chinese).
29. Lartaud-Idjouadiene I, Niederhoffer N, Debets JJ, StruykerBoudier HA, Atkinson J and Smits JF: Cardiac function in a rat model of chronic aortic stiffness. Am J Physiol 272: H2211-H2218, 1997.

30. Watson KE: Pathophysiology of coronary calcification. J Cardiovasc Risk 7: 93-97, 2000

31. Rajamannan NM, Sabramanian M, Rickard D, Stock SR, Donovan J, Springett M, Orszulak T, Fullerton DA, Tajik AJ, Bonow RO and Spelsberg T: Human aortic valve calcification is associated with an osteoblast phenotype. Circulation 107: 2181-2184, 2003.

32. Hagiwara H, Hiruma Y, Inoue A, Yamaguchi A and Hirose S: Deceleration by angiotensin II of the differentiation and bone formation of rat calvarial osteoblastic cells. J Endocrinol 156: 543-550, 1998.

33. Zhang J, Fu M, Myles D, et al: PDGF induces osteoprotegerin expression in vascular smooth muscle cells by multiple signal pathways. FEBS Lett 521: 180-184, 2002.

34. Nakazato M, Murakami N, Date Y, et al: A role for ghrelin in the central regulation of feeding. Nature 409: 194-198, 2001.

35. Jono S, Peinado C and Giachelli CM: Phosphorylation of osteopontin is required for inhibition of vascular smooth muscle cell calcification. J Biol Chem 275: 20197-20203, 2000.

36. Wiley KE and Davenport A: Comparison of vasodilators in human internal mammary artery: ghrelin is a potent physiological antagonist of endothelin-1. Br J Pharmacol 136: 1146-1152, 2002

37. Zaidi M, Alam AS, Bax BE, et al: Role of the endothelial cell in osteoclast control: new perspectives. Bone 14: 97-102, 1993.

38. Stern PH, Tatrai A, Semler DE, et al: Endothelin receptors, second messengers, and actions in bone. J Nutr 125 (Suppl 7): S2028-S2032, 1995.

39. Masukawa H, Miura Y, Sato I, Oiso Y and Suzuki A: Stimulatory effect of endothelin-1 on Na-dependent phosphate transport and its signaling mechanism in osteoblast-like cells. J Cell Biochem 83: 47-55, 2001. 